\title{
Entre o texto e a vida: uma leitura sobre as políticas de educação especial
}

Carla K. Vasques'

Simone Moschen'

Roselene Gurskil

\section{Resumo}

À margem da agenda política do Estado, a educação especial tradicionalmente se organizou como atendimento educacional especializado substitutivo ao ensino comum, em classes e escolas especiais. Nas últimas décadas, o Brasil, em consonância com movimentos internacionais, estabeleceu uma série de leis, políticas e programas para combater as desigualdades e a exclusão escolar. Nesse movimento, sujeitos com transtornos globais do desenvolvimento (TGD), tradicionalmente apartados dos processos de escolarização, são recebidos nas salas de aula e no velho pátio da escola. Quais racionalidades sustentam as formas de nomear e identificar esses alunos? Como compreender as relações entre os diagnósticos, as políticas e a inscrição das (im)possibilidades escolares? Em que medida as políticas inclusivas de educação especial desconstroem sentidos que relacionam os TGD à ineducabilidade, ou, ainda, a diferença à anormalidade e à inferioridade? 0 presente ensaio discute a implementação das diretrizes inclusivas considerando o texto político e seus efeitos no contexto da prática. A hermenêutica filosófica oferece os tempos e os focos da leitura. 0 argumento é tecido com e a partir das falas de um aluno e de professores, em diferentes campos de pesquisa. Do texto à vida, o incremento das matrículas; a proliferação dos sentidos sobre esses alunos e as possibilidades escolares; a atualização de antigos impasses perante o novo, o diferente. Se, no âmbito dos princípios, são reconhecidas a igualdade e as diferenças, na concretude das escolas ainda persiste a noção do diferente como desigual. Da inclusão ao pertencimento, aposta-se no diálogo como valoração da alteridade e condição de pertença.

\section{Palavras-chave}

Educação especial - Transtornos globais do desenvolvimento Políticas inclusivas - Desigualdade - Diferença.

I- Universidade Federal do Rio Grande do 


\title{
Between text and life: a reading of special education policies
}

\author{
Carla K. Vasques' \\ Simone Moschen \\ Roselene Gurskil
}

\section{Abstract}

On the sidelines of the State political agenda, special education has traditionally been organized as the specialized educational catering that substitutes regular teaching in special classes and schools. In the last decades, Brazil, in tune with international movements, has established a series of laws, policies and programs to tackle inequalities and social exclusion. In such movement, subjects with global learning difficulties (GLD), traditionally excluded from schooling processes, are accepted in the classroom, and in the old school yard. What rationalities give support to the forms of naming and identifying who are these pupils? How do we understand the relation between the diagnostics, the policies, and the inscription of the school (im) possibilities? To what extent inclusive policies of special education deconstruct the meanings that associate GLDs with ineducability or, still, difference with abnormality and inferiority? This essay discusses the implementation of guidelines of inclusion considering the political text and its effects on the context of the practice. Philosophical hermeneutics offers the times and focus for this reading. The argument is woven with and from the speeches of a pupil and of teachers in different fields of research. From text to life, the increase in enrolments; the proliferation of the meanings about these pupils and the school possibilities; the re-enactment of old impasses faced with the new, the different. Although within the sphere of principles equality and differences are both recognized, in the concrete life in schools the notion of the different as unequal still endures. From inclusion to belonging, we put our hopes here in the dialogue as valuation of alterity and requirement of belonging.

\section{Keywords}

Special education - Global learning difficulties - Inclusive policies Inequality - Difference.

I- Universidade Federal do Rio Grande do

Sul, Porto Alegre, RS, Brazil.

Contacts:k.recuero@gmail.com;

simonemoschen@gmail.com;

roselenegurski@terra.com.br 
O que importa não é somente escutar coisas uns dos outros, senão escutar uns aos outros. Unicamente isso é compreender. Hans-Georg Gadamer

A inclusão, compreendida a partir do movimento que defende a universalização dos direitos humanos, desponta como perspectiva norteadora das políticas públicas, das propostas de atendimento e de formação profissional em diferentes áreas do conhecimento e setores sociais. ${ }^{1}$ Nas últimas décadas, a educação especial tem contemplado os influxos dessa discussão no que se refere ao acesso de alunos com deficiências no ensino comum e, sobretudo, ao pertencimento a esses espaços a partir do reconhecimento da alteridade. Tais proposições suscitaram um grande número de debates e produções voltadas para a análise do atendimento educacional especializado, da formação de professores, do currículo e da gestão, entre outros temas. Apesar desses movimentos, é ainda amplo o desconhecimento sobre a educação escolar em face das demandas inclusivas (BAPTISTA; CAIADO; JESUS, 2008).

0 presente artigo aborda tais temáticas a partir do campo sujeitos da educação especial. Considerado um tema histórico na área, ele implica disputas conceituais e ideológicas a respeito da identificação, das terminologias, da avaliação, do diagnóstico e dos desdobramentos dessas questões nas formas organizativas do trabalho pedagógico (GARCIA, 2006; VASQUES, 2008). As implicações dessa discussão não se resumem às convenções pragmáticas e aos seus efeitos de razão classificatória. Conforme afirmam Figueiredo e Tenório (2002, p. 42),

assim como um diagnóstico decorre de uma definição prévia (implícita ou explícita) sobre a função terapêutica, também influencia, ele mesmo, os alcances de um tratamento.

1- Compreendemos a temática da inclusão e exclusão em relação aos direitos à educação, à igualdade e à diferença.
Da mesma maneira, os percursos educacionais encontram-se atrelados à compreensão do educador, da escola e das instituições em relação aos sujeitos que educam e aos serviços que prestam. Quais racionalidades sustentam as formas de nomear e identificar os alunos tidos como especiais? Como compreender as relações entre os textos diagnósticos, políticos, e a inscrição das (im)possibilidades escolares? Em que medida as políticas inclusivas de educação especial desconstroem sentidos que relacionam a diferença à anormalidade $\mathrm{e}$ à ineducabilidade? Focaremos essas questões considerando os sujeitos com transtornos globais do desenvolvimento (TGD).

Com a Politica Nacional de Educação Especial na Perspectiva da Educação Inclusiva (BRASIL, 2008), inscreve-se uma nova realidade: crianças e adolescentes com TGD, autistas e psicóticas, tradicionalmente apartadas dos processos de escolarização, ganham espaço nas salas de aula e no velho pátio das escolas. Em consequência de uma estruturação psíquica singular, esses sujeitos podem apresentar comportamentos estereotipados, falas descontextualizadas, escritas e leituras presas na literalidade ou com sentido errante. Estudos realizados a partir da produção discente nos últimos vinte anos indicam que tais diferenças são percebidas como impedimentos e justificam a ausência de escola ou o encaminhamento para espaços reeducativos, com vistas à adaptação comportamental (VASQUES, 2008, 2009). A fim de construir outro horizonte compreensivo, trilharemos um caminho em diálogo com a hermenêutica filosófica.

Hans-Georg Gadamer (1900-2002), filósofo alemão, em Verdade e método (obra de 1960), discute o acontecer da compreensão; o compreender por meio da interpretação; o diálogo entre a tradição e o intérprete; os aspectos linguísticos da compreensão versus a impossibilidade de uma interpretação objetiva.

A compreensão é uma pré-condição para a existência do homem, é a consciência de que ele próprio e o mundo existem. 0 objetivo da 
hermenêutica filosófica não é validar uma interpretação e compor uma verdade unitária. Sua reflexão implica renunciar à busca de um fundamento último, sólido, do qual emanam certezas absolutas.

Palavras em um pedaço de papel. Um poema? Um aluno? Gadamer (2007) universalizou o compreender: o homem é um ser hermenêutico. 0 objeto da hermenêutica são os símbolos, os signos e todas as manifestações da vida, ou seja, as produções culturais, as políticas, as mediações humanas. Como se compreende? Quando leitor, historicidade e texto dialogam. Essa é a linguisticidade da experiência hermenêutica. Tal encontro não implica síntese, mas ampliação dos horizontes; esse é o desafio e a arte do compreender, ler e dialogar. Existe uma dinâmica complexa e delicada entre a objetividade e a subjetividade, o novo e o mesmo, o conhecido e o desconhecido. Nesse movimento, a compreensão não trata de um simples modo de conhecer, mas implica uma maneira de ser e de se relacionar com o estranho. Nas palavras de Hermann (2011, p. 145), o outro, o diferente, na medida em que nos retira do habitual e do familiar, pode desconstruir a unidade inquestionável que nos é dada pela tradição:

Se a tradição tem o papel significativo no fenômeno da compreensão, na medida em que contém a historicidade que nos constitui e que é coextensiva à vida que vivemos; a estranheza, por sua vez, atua como distanciamento temporal, gerando a tensão produtiva com a qual se estabelece a própria situação hermenêutica. Nessa tensão entre familiaridade e estranheza se dá a tarefa da compreensão que abre um horizonte novo, onde o sujeito que se expõe ao outro, é por ele interrogado.

É no jogo entre o familiar e o estranho, o legível e o ilegível, que a perspectiva gadameriana situa a compreensão dos fenômenos políticos. Entre tradição, texto e intérpretes, uma delicada trama institui e modifica sentidos, ressignifica diretrizes, alternativas, impasses e disputas interpretativas. Não há um único sentido e tampouco se pode tudo saber, conhecer, interpretar. Esse limite permite contrapor a objetivação, a domesticação e a tiranização do outro, do diferente, por vezes engendradas em leituras ingênuas ou politicamente corretas. Conforme afirma Hermann (2011, p. 145):

a hermenêutica constitui-se numa possibilidade de relação entre o eu e a alteridade, que supera a exclusão e a apropriação, uma vez que o diálogo só pode existir se houver um outro.

Com tal impulso ético, propomos a conversação entre as políticas de educação especial, as razões diagnósticas e as falas de um aluno, de professores e gestores. 0 argumento é tecido a partir de diversos campos e tempos de pesquisa e sua urdidura se dá na forma de um ensaio. Para tanto, buscamos inspiração metodológica nas palavras de Adorno (2003, p. 29-30):

0 ensaio exige, ainda mais do que procedimento definidor, a interação recíproca de seus conceitos no processo da experiência intelectual. Nessa experiência, os conceitos não formam um continum de operações, o pensamento não avança em um sentido único; em vez disso, os vários momentos se entrelaçam como um tapete. Da densidade dessa tessitura depende a fecundidade do pensamento.

Com os fios da teoria, das normativas legais que dão borda à experiência da vida, das falas recolhidas dos encontros de pesquisa com alunos, professores e gestores, tramamos as perguntas que orientam nossa reflexão sob a inspiração do ensaio, buscando dar consistência aos argumentos pela tessitura dos fios, e não pela busca de uma definição. 
Tempos de inscrição: o texto político e o nascimento de um aluno

[...] já perdi muito tempo nos estudos. Entrei tarde porque estava nas clínicas, agora tenho que correr atrás... Não posso ficar fora das escolas novamente!!!

Eu posso ficar encostado como na escola antiga. Foi só depois que fui aluno de verdade. Sinto saudades do meu tempo de escola, de aluno. Agora ninguém quer saber de mais nada... aqueles eram bons tempos que não voltam mais. Minha vida está uma droga e ninguém faz nada... Eu não posso fazer sozinho. Eu só sou paciente agora... Só fui aluno na escola Jean Piaget, só fui alguém quando era aluno.

(Rodrigo $\left.{ }^{2}\right)$

As palavras de Rodrigo ecoam como marcas de um fracasso. Professores, gestores e pesquisadores não conseguiram sustentar um lugar possível e desejado: o lugar de aluno. Leis, contratos e teorias foram insuficientes: frágeis perspectivas perante lentes que liam em Rodrigo a imagem-síntese, negada e assustadora, de uma infância que teimava em existir. Desse lugar de insuficiência, como vulto do aluno que não fora, ele falava: "Eu sei que a lei me ampara, a nova lei da educação! É necessária uma intervenção... não posso sozinho!”.

0 ano era 1998 e, no âmbito normativo, tais sujeitos eram considerados alunos da educação especial por apresentarem condutas típicas de alterações psiquiátricas, psicológicas ou neurológicas. Pela política de educação especial vigente (BRASIL, 1994), o ingresso no ensino comum dar-se-ia sempre que possível, a depender do comprometimento.

Sob os auspícios da integração instrucional, ou seja, da normatização e da adaptação, a escola era uma possibilidade somente àqueles com

condições de acompanhar e desenvolver as atividades curriculares programadas do ensino comum, no mesmo ritmo que os alunos ditos normais. (BRASIL, 1994, p. 19)

2- Considerando as diretrizes éticas de pesquisa, resguardou-se 0 anonimato dos sujeitos e das instituições envolvidas.
Como compreender a relação entre o texto político e a inscrição de percursos escolares?

À margem da agenda política do Estado, a educação especial tradicionalmente se organizou como atendimento educacional especializado substitutivo ao ensino comum, em classes e escolas especiais, ou seja, em espaços e propostas diferenciadas para aqueles que, por suas qualidades sociais, culturais, genéticas, comportamentais etc., diferiam da normalidade.

$\mathrm{Na}$ época, a gestora de uma escola pública afirmara:

Rodrigo não pode permanecer na escola regular, sofreria muito por não acompanhar a turma. Os colegas também seriam prejudicados, em função dos ritmos. 0 melhor é um atendimento especializado, para atender suas diferenças.

Sucessivas portas se fecharam. Rodrigo, como tantos outros, desqualificava a sala de aula comum e a aprendizagem dos iguais. Sua presença era impossível. Sua diferença, desigualdade. Sua desigualdade, incapacidade. Para as lentes do Estado, dos professores e dos especialistas, ser diferente era ser anormal, o que justifica a desigualdade de escolarização, de acesso e permanência na escola. 0 diferente feito desigual é responsável pela desigualdade escolar. Para Arroyo (2010), essa perspectiva possui raízes profundas na cultura escolar brasileira.

A persistência, o crescimento e o aprofundamento desse quadro, em conjunto com a universalização da educação básica e as conferências internacionais que versam sobre os que estão do lado de fora, introduziram no cenário político as diretrizes inclusivas. Nesse sentido, o Brasil implementou uma série de leis, políticas e programas voltados para a redução da desigualdade e para a inclusão escolar. Ainda nas palavras de Arroyo (2010), uma nova perspectiva se constitui: o diferente não mais é visto como desigual, mas como excluído. Reescrevem-se as agendas sociais e políticas... 
Nesse movimento, a educação especial passa a ser definida como

uma modalidade de ensino que perpassa todos os níveis, etapas e modalidades, realiza o atendimento educacional especializado, disponibiliza os serviços e recursos próprios desse atendimento e orienta os alunos e seus professores quanto a sua utilização nas turmas comuns do ensino regular. (BRASIL, 2008)

\section{Como diretrizes, propõe-se}

assegurar a inclusão escolar de alunos com deficiência, transtornos globais do desenvolvimento e altas habilidades/superdotação, orientando os sistemas de ensino para garantir: acesso ao ensino regular, com participação, aprendizagem e continuidade nos níveis mais elevados do ensino; transversalidade da modalidade de educação especial desde a educação infantil até a educação superior; oferta do atendimento educacional especializado; formação de professores para o atendimento educacional especializado e demais profissionais da educação para a inclusão; participação da família e da comunidade; acessibilidade arquitetônica, nos transportes, nos mobiliários, nas comunicações e informação; e articulação intersetorial na implementação das políticas públicas. (BRASIL, 2008)

0 atendimento educacional especializado garantido na Constituição Federal como preferencialmente no ensino regular é ressignificado: todos devem estar na escola comum!

Para além de um documento orientador, a Política passa a se constituir um marco na organização do sistema educacional inclusivo [...] fortalecendo o conceito de educação especial que não concebe, nem em caráter extraordinário, a utilização desse atendimento em substituição à escolarização realizada no ensino regular. (GRIBOSKI, 2008, p. 57)
0 documento inova ao deslocar o olhar do aluno para os contextos institucionais, pedagógicos, culturais, históricos; ao questionar diagnósticos realizados como categorizações fechadas sobre quem são os sujeitos e quais são suas possibilidades subjetivas e educacionais.

As definições do público alvo devem ser contextualizadas e não se esgotam na mera categorização e especificações atribuídas a um quadro de deficiência, transtornos, distúrbios e aptidões. Considera-se que as pessoas se modificam continuamente transformando o contexto no qual se inserem. (BRASIL, 2008)

No âmbito do ordenamento jurídico, as deficiências, pela primeira vez, são descritas não só como alterações orgânicas estruturais ou funcionais, mas como decorrentes também das relações humanas, econômicas, sociais etc. $\mathrm{Na}$ constituição do sujeito como deficiente, deficitário, ou não, sublinha-se a força dos encontros, da cultura e das políticas como elementos possibilitadores ou limitadores do humano.

Nesse texto orientador e nos documentos legais que o sucederam, alunos como Rodrigo, agora pertencentes à categoria dos TGD, têm sua escolarização pela primeira vez garantida. 0 ordenamento legal transforma a escola e, como demonstrado na tabela 1, seu primeiro efeito é o incremento das matrículas.

Tabela 1 - Total de matrículas de alunos com TGD no Brasil, por níveis de ensino, nos anos de 2009 e 2010

\begin{tabular}{|c|c|c|c|c|c|c|}
\hline \multirow{2}{*}{ TGD/Ano } & \multicolumn{2}{|c|}{ Autismo } & \multicolumn{2}{|c|}{$\begin{array}{l}\text { Síndrome de } \\
\text { Asperger }\end{array}$} & \multicolumn{2}{|c|}{ Psicose infanti } \\
\hline & 2009 & 2010 & 2009 & 2010 & 2009 & 2010 \\
\hline Total de matrículas & 2.430 & 2.528 & 3.693 & 4.708 & 8.118 & 9.200 \\
\hline Creches & 133 & 150 & 315 & 345 & 71 & 126 \\
\hline Pré-escola & 271 & 301 & 540 & 684 & 686 & 668 \\
\hline Ensino fundamental & 1.465 & 1.617 & 2.177 & 2.857 & 5.988 & 5.069 \\
\hline
\end{tabular}

Fonte: MEC/INEP 
Se o acesso à escolarização é significativo, pouco ele diz da permanência. 0 texto político estabelece contornos de uma realidade cuja qualidade se joga na arena de disputas, resistências e embates. A letra da lei não circunscreve completamente as possibilidades do acontecimento. Como letra, implica leitura. E como leitura, implica - por mais que se queira varrer o equívoco de seu enunciado - abertura aos sentidos. A leitura nunca é linear, unívoca ou consensual...

\section{Tempos de interpretação: quem} são os alunos com TGD? Quais são as possibilidades escolares?

Não sei de onde estes nomes aparecem: antes condutas típicas, agora TGD, TID, TDI! 0 que significa tudo isto?

O que teria a escola a oferecer para tais crianças? Esses meninos e meninas que rodopiam pelas salas, que não falam, mas apenas murmuram, poderiam ler? Escrever? Fazer contas? Dessas crianças de cristal, o que se pode esperar? Como investir em quem parece não apreender?

Com diagnósticos como traços autistas, autismo ou psicose o professor fica autorizado a não apostar no aluno. Isso inviabiliza qualquer proposta de trabalho.

0 diagnóstico de psicose infantil, autismo, transtorno global do desenvolvimento, entre outros, tem uma história recente e complexa. Inicialmente desconhecido como entidade, fazia parte do grande grupo das idiotias, sendo mais tarde descrito sob nomes e formas diversas.

Ajuriaguerra (1980) afirma que a evolução desses conceitos e das concepções relativas às deficiências em geral ocorreu a partir do século XX. Do campo médico derivam explicações organicistas, deterministas, centradas na dimensão biológica como causa e limite. A psicologia, por sua vez, oferece os recursos necessários para classificar os graus de comprometimento: os testes psicométricos. Os primeiros testes de inteligência foram elaborados para diferenciar as crianças capazes das supostamente incapazes de beneficiar-se da escola pública. Os conceitos mais populares da psicometria foram os de idade mental e quociente intelectual. A racionalidade médico-psicológica marcará de forma indelével o conhecimento sobre as possibilidades terapêuticas e educacionais até a contemporaneidade: os diferentes feitos anormais.

A publicação de Psicopatologia geral, do psiquiatra e filósofo Karl Jaspers (1883-1969), no início do século XX, transforma a psicopatologia em disciplina organizada. Descrever e classificar, sistemática e detalhadamente, as doenças mentais: essa é a intenção de Jaspers. A psicologia profunda de Sigmund Freud (18561939) faz a grande ruptura epistemológica. Nas páginas de A interpretação dos sonhos (1900) nasce a psicanálise. Em sua letra, rompem-se as margens que separam claramente a doença da saúde mental: Freud postula que o sujeito - louco ou não -, sempre que fala, fala de - e a partir de - seu pathos, aqui confundido com a trama discursiva que o constitui. As manifestações do pathos, elementos da psicopatologia, constituem os princípios presentes em estudos, pesquisas e tratamentos do psicopatológico, sejam eles feitos pela psiquiatria, pela psicanálise, pela psicologia ou pela educação. Como não existe uma rede significante única, uma trama discursiva última que acolha os elementos básicos da psicopatologia, o fenômeno das doenças mentais ou do sofrimento psíquico humano foi repartido em uma pluralidade de abordagens (CECCARELLI, 2003).

Desde o encontro de Itard e Victor, as tentativas de tratar e educar crianças com graves problemas de desenvolvimento geram debates acalorados. Confundem-se as fronteiras entre doença mental e deficiência mental, entre clínica e escola, na infância.

Em 1943, Léo Kanner (1894-1981) publica Os distúrbios autísticos do contato afetivo. Sua obra é fundamental para a descrição de um novo quadro e campo: o autismo infantil precoce (AIP) e a psicopatologia infantil. As onze crianças atendidas por ele apresentam diferentes graus de distúrbios. A evolução e o prognóstico são também singulares. À parte a singularidade, segundo 
o autor, o AIP forma uma síndrome única, marcada pelas dificuldades em estabelecer relações de maneira normal com pessoas e situações desde o princípio da vida.

Sob a rubrica 295 - esquizofrenia tipo infantil, surge a primeira referência às psicoses infantis e ao autismo nos manuais classificatórios, como a CID-10 (Classificação Internacional das Doenças) e o DSM (Manual Diagnóstico e Estatístico de Transtornos Mentais). Tais publicações dizem-se ateóricas e afirmam ofertar critérios objetivos e verificáveis para o processo diagnóstico nos âmbitos da saúde e da educação. Após múltiplas versões, segundo o DSM, o autismo passa a ser compreendido como um distúrbio do desenvolvimento; não se utiliza mais o termo infantil, uma vez que tal distúrbio acompanhará o indivíduo pela vida toda; além disso, ele passa a ser descrito como um conjunto de patologias, uma síndrome. Tem-se também a noção de autismo como um continuum, variando a sintomatologia de acordo com o comprometimento cognitivo. Surgem os autistas de alto ou baixo funcionamento. No DSM-IV, em 1994, são acrescidas as síndromes de Aspeger e de Rett. Já na revisão de 2002 da obra (DSM-IV-TR), apresenta-se a classificação de transtornos globais do desenvolvimento (TGD), os quais são definidos como um conjunto de condições caracterizado pela variabilidade de sintomatologias.

A CID-10 (OMS, 2003) é a referência oficial adotada no Brasil desde 1996; considerada em comparação ao modelo do DSM, as diferenças são poucas, porém significativas: manutenção dos termos infantil, psicose infantil e autismo atípico, bem como do contexto da infância como característica desses quadros; e adoção de critérios diagnósticos mais amplos, ou seja, menos definidos. Ao manter tais nomes e fronteiras um pouco mais borradas, que evocam as diferentes tradições psicopatológicas, a CID-10 abre espaço para que se coloque em questão o que é apresentado como certeza pelo DSM.

0 diagnóstico e a psicopatologia descritivos não são interpretados uniformemente.
Alguns autores não problematizam tais referências, tratando-as genericamente, ou seja, utilizam-nas como forma de identificar o sujeito a ser pesquisado, sem contextualizar a historicidade dos conceitos, seus limites e implicações; outros se situam nesse referencial enquanto a etiologia não é mais bem definida, o que temporariamente impossibilita um tipo diverso de classificação; há também os que se afırmam categoricamente ateóricos. No gesto que toma nas mãos o texto que constitui esses manuais, verificam-se rasuras, ruídos na leitura, algumas passagens sublinhadas, outras esquecidas...

Fala-se de psicose infantil e autismo, ou de psicose e autismo como duas situações diferenciadas. Outros dizem que nada disso existe, que o correto é referendar autismo ou espectro autista, conforme a noção de continuum, ou seja, um mesmo quadro, com diferentes graus de gravidade. Tem-se a ideia de síndrome: de Kanner, de Asperger, de autismo infantil precoce, de transtorno desintegrativo da infância, de autismo atípico. Há aqueles que afirmam: falamos de erros metabólicos, de transtornos neuropsiquiátricos que, mesmo sem um marcador biológico identificado, implicam déficits cognitivos. Outros replicam: falamos da loucura e, mais ainda, da loucura na infância, possuidora de características diferenciadas da loucura do adulto. Aí se diz, por exemplo, das mães geladeiras, culpadas pelas fortalezas vazias em que se transformaram seus filhos. Ou das psicoses e do autismo infantil como posições subjetivas. 0 autista da neurociência difere radicalmente do autista da psicanálise. A regra é o desacordo. A unidade de sentido é ilusória...

Dessas turvas lentes deriva a identificação dos alunos com transtornos globais do desenvolvimento:

aqueles que apresentam um quadro de alterações no desenvolvimento neuropsicomotor, comprometimento nas relações sociais, na comunicação, estereotipias motoras. Incluem-se nessa definição alunos com autismo clássico, síndrome de 
Asperger, síndrome de Rett, transtorno desintegrativo da infância (psicoses) e transtornos invasivos sem outra especificação. (BRASIL, 2008)

Quem são esses alunos? Como eles aprendem? No campo da educação especial, o diálogo com os sistemas diagnósticos e as lógicas classificatórias é intenso, porém nem sempre suficientemente esclarecido. No texto da política não há referência sobre a historicidade das nomenclaturas e descrições, tampouco sobre as múltiplas e divergentes teorias. 0 ponto crucial da ausência de reflexão sobre os determinantes históricos e as concepções de sujeito presentes na elaboração dos diagnósticos está no fato de que diferentes entendimentos imprimem percursos escolares também diversos, cifrando destinos distintos.

0 lugar de sujeito, do professor e de aluno, fica subtraído, economizado, por uma causalidade que se impõem antes mesmo de qualquer ato que cada um deles possa inscrever. Uma causalidade que não se constrói a partir dos efeitos das práticas e dos encontros, mas que chega antes - antes dos próprios sujeitos -, retira da cena a responsabilidade. (RICKES, 2004, p. 12)

Para Marchezan (2009), a classificação representa não uma tentativa de negar o outro, mas de fazê-lo conhecido. A demarcação de suas características torna esse outro diferente, interpretável. Termos como transtornos globais, desintegrativos, invasivos, do desenvolvimento, autismo e psicose são, na dialética da compreensão, tentativas de constituir um aluno, uma educação, um professor - vale sublinhar que a educação e o professor, entidades aparentemente apartadas desse debate na medida em que conservam sua existência para além dele, também têm seu sentido e lugar construídos pelas concepções que embasam esses construtos diagnósticos.

0 diálogo apresentado a seguir, entre professoras com experiência na educação especial, é ilustrativo das múltiplas formas de interpretar o texto político e os ditames diagnósticos: produzindo práticas pedagógicas relacionadas à diferença pelo viés da desigualdade e da anormalidade, ou pela lente da alteridade.

Professora A: Oi, onde tu estás agora?

Professora B: Eu to na sala regular, com alunos autistas.

Professora A: Cruzes, não tem pior! Trabalho com surdo, cego, qualquer deficiente... mas com autista não! Parece bicho!

Professora B e C: Aii...

Professora A: É verdade! 0 cara fica lá, parado, olhando pro nada... Sim, porque pra mim ele não olha e...

Professora C: ... Mas o cego também fica vendo nada e isso não te atrapalha?

Professora A: É completamente diferente. Tu disse tudo agora! 0 cego não me vê, mas sabe que estou ali, precisa de mim, me chama e me olha... Eu sou a professora dele. 0 autista não! Ele não quer saber de mim, não quer saber de nada... Aí não dá! $\mathrm{Eu}$ achava que tinha de ficar na APAE, esses casos são de APAE e olhe lá!

Professora B: Olha, é complicado... Mas não acho que seja tão assim! Tem que estar na escola regular, com os outros...

Professora C: Sabe o que eu acho mais complicado, que quando a gente tá na APAE daqui, por exemplo, tem um trabalho específico pra esse aluno, que já vem pronto. 0 aluno pode nem estar, mas eu já sei tudo que tenho de trabalhar antes dele chegar! Agora isso também tá acontecendo nas salas multifuncionais, de apoio! Tá tudo pronto, ele é autista, psicótico, então não precisa nem vir, porque eu já sei o que vou fazer! Aí fica sem sentido. É esse modelo, fechado, que tá chegando nas salas de aula regular! Quem é que vai dizer que isso é inclusão? Ele fica completamente separado, com um trabalho que não integra em nada... 
Professora A: Mas ele é autista, então é isso mesmo! E tá na sala de aula, tá incluído!!! Professoras B e C (juntas): Ah... Não, não é a mesma coisa... Então quer dizer que tudo é igual, que basta saber que ele é isso ou aquilo e tá lá...

Professora A: Nesses casos, não vai ser mais do que isso...

Professora B: Dá pra fazer um monte de coisas... Eles vão indo, vão aprendendo... É difícil explicar, compreender, sei lá... Mas eles têm que estar na escola, ser aluno é bom...

0 processo de inclusão escolar envolve diferentes formas e tempos de olhar/ler o aluno. Se as crianças ditas normais trazem consigo a ilusão de que sabemos a respeito dessa trajetória e do processo de ensino-aprendizagem, aquelas com TGD suspendem certezas, tornando-se, muitas vezes, intraduzíveis para nossas lentes: "0 cego não me vê, mas sabe que estou ali, precisa de mim, me chama e me olha... Eu sou a professora dele. 0 autista não! Ele não quer saber de mim, não quer saber de nada... Aí não dá!". Se nada há de um aluno ali, se seus comportamentos, suas respostas e relações pouco se assemelham aos textos aprendidos, às expectativas e representações relativas ao que é ser criança e ser aluno, como ser professor? E não havendo professor, como constituir-se como aluno? 0 diálogo inviabiliza-se, cegando possíveis leituras e horizontes compreensivos.

No campo da educação especial, é necessário problematizar tais questões, não no sentido de oferecer uma ou outra teoria como resolução dos impasses que o encontro com tais crianças engendra, mas no de que essas concepções circulam sem maiores questionamentos, esvaziadas de seu valor de conceito. E o aluno é reduzido ao seu comportamento. 0 apego descritivo às síndromes e constelações de sintomas permanece furtivo e não esclarecido. A realidade do autista lhe é natural, sendo explicada pela ciência e explicitada por meio do diagnóstico, das classificações e das avaliações.
Outra leitura, contudo, é viável, como nos fala uma professora:

Tudo começou com a política. Foi pela orientação legal que abri meus olhos [...]. Não sei muito bem o que Mathias [aluno com autismo] tem. Sou confrontada todo dia pelo dilema de dar uma explicação... para mim, para os outros professores, para as outras crianças, para os outros pais. Eu não tenho explicação, eu não tenho certeza... Tenho uma aposta, um projeto, uma vontade. [...] Um olhar meu, que se sustenta no olhar do Mathias e nos olhares da escola, da lei. Uma história feita de olhares. Olhares que possibilitam o ingresso e a permanência de Mathias em uma escola regular. É pouco? É sufıciente? Não sei... Mas mesmo não sabendo, é minha responsabilidade construir e sustentar esse saber possivel.

Como compreender as relações entre os textos diagnósticos, políticos, e a inscrição das (im)possibilidades escolares? A experiência da escolarização envolve uma construção compartilhada. Os preconceitos e a antecipação que deles advém não são considerados resíduos de uma consciência que distorce a realidade, mas focos que permitem um primeiro movimento compreensivo, uma primeira mirada. Nesse movimento, é fundamental deslocar o foco do sujeito com autismo, psicótico, para o professor - o outro que lê, interpreta e constrói possibilidades -, implicando-o na construção de uma perspectiva. Trata-se de problematizar a relação entre comprometimento e perspectivas educacionais também em termos de trajetórias, políticas e serviços. Dito de outra forma, analisar a intervenção e o contexto é fundamental para repensar os sujeitos, pois o conhecimento que se pode ter deles depende diretamente de análises que integrem a historicidade das relações e das instituições que forjam e sustentam formas de viver, as quais muitas vezes nos são apresentadas como quadros predefinidos e estáticos: 0 autista, o deficiente mental etc. 
Gadamer afırma que não somos reféns de nossos pressupostos, porém não possuímos total domínio sobre eles. Termos como autismo, psicoses infantis, TGD etc. referem-se a conceitos e construções linguísticas oriundas de diferentes racionalidades e epistemologias, ou seja, de sistemas mais ou menos fechados que armam determinadas perspectivas. A interpretação ocorre a partir dos horizontes compreensivos. Trata-se da historicidade, das racionalidades, das condições de produção dos textos, dos sentidos hegemônicos que amalgamam cada perspectiva. Há sempre o risco de essencializar ou naturalizar nossas lentes e concepções, sobretudo se generalizamos ou desconsideramos os limites do conhecimento, se despolitizamos seu conteúdo. Daí a necessidade do autoesclarecimento constante, da reflexão sobre as bases de nosso proceder.

\section{Tempos de compreender:}

(des)igualdade e diferença em

educação especial

0 autista da política não é o mesmo autista que chega às salas de aula. Temos de descobrir, criar, inventar um aluno, uma professora, uma prática coerente.

[...] Ele estava ali, o tempo todo e não o vi... Porque era um TGD, um autista, imaginava que ele não poderia me entender [...]. Ofereci tão pouco... Poderia ter oferecido mais... Poderia ter oferecido um olhar de reconhecimento..

0 homem pode ser lido. A vida humana é análoga a um texto. A hermenêutica filosófica estende essa noção para todos os campos da existência humana. Assim como um texto, a vida expressa sentidos construídos por meio da leitura, da interpretação e da compreensão. Dessa maneira, a leitura torna-se uma metáfora para problematizar a pluralidade das formas de ser e estar, incluindo os fenômenos políticos e educacionais. Somos todos livros/textos inacabados, à espera de leitores generosos...

0 presente ensaio abordou a temática da desigualdade e da diferença a partir dos sujeitos da educação especial. 0 foco argumentativo foi a escolarização de alunos com transtornos globais do desenvolvimento.
Considerando-se os diferentes tempos, os documentos normativos e as razões diagnósticas, percebeu-se que a experiência escolar envolve uma construção compartilhada a partir dos pressupostos a respeito de escola, educação, sociedade etc. 0 texto político - suas linhas, margens e entrelinhas - oferece uma primeira mirada, estabelece as bordas de uma arena onde se dá o balé dos significantes que, ao se articularem, engendram sentidos singulares. Quais são as possíveis significações?

Responder a essa pergunta não constituiu o objetivo deste ensaio. Ainda assim, esteve em nossa mira situar a necessariedade de sua colocação em cena. Em consonância com a inspiração ensaística, não buscamos começar "com Adão e Eva, mas com aquilo que se deseja falar; diz o que a respeito lhe ocorre e termina onde sente ter chegado ao fim, não onde nada mais resta a dizer..." (ADORNO, 2003, p. 16-17).

Com as diretrizes inclusivas, um novo capítulo da educação especial se inscreve. 0 direito à educação garante acesso irrestrito à escolarização. Os direitos à igualdade e à diferença reorganizam os serviços, os conceitos e os profissionais da escola. Em que medida as políticas inclusivas de educação especial desconstroem sentidos que relacionam a diferença à desigualdade, à anormalidade e à ineducabilidade?

Para Arroyo (2010), pela polarização que estabelecem - dentro-fora, incluído-excluído -, as diretrizes inclusivas enfraquecem os ideais de superação das desigualdades na medida em que deslocam o foco para questões de pertencimento ou não aos espaços universais. Nesse movimento, correm sempre o risco de, ao invés de desconstruírem, reforçarem sentidos que associam a diferença à desigualdade, à inferioridade e ao não pertencimento. Trata-se de um perigo iminente que, para ser transposto, exige um trabalho articulado no cotidiano das escolas, pois da letra da lei à atualização na vida há um longo caminho a ser percorrido. A letra abre espaço à produção de um sentido, mas não garante o vetor em que ele se inscreverá. 
São múltiplas as formas de interpretar a política, de produzir e reproduzir sentidos relacionados à diferença pelo viés da desigualdade e/ou da identidade. Se no âmbito dos princípios são reconhecidas a igualdade e as diferenças, na concretude das escolas ainda persiste a noção do diferente como desigual: "tá na sala de aula, tá incluído!”. A escola equaciona o diferente à anormalidade e acaba por reproduzir - e justificar - a desigualdade: "ele é autista, é isso mesmo!”. Nesse contexto, o fascinante e eficaz conhecimento científico oferecido pelos manuais classificatórios justifica compreensões e trajetórias escolares empobrecidas e objetivadoras: "Com diagnósticos como traços autistas, autismo ou psicose o professor fica autorizado a não apostar no aluno”. A eficácia e a fascinação derivam da forma: um modelo descritivo, classificatório, no qual tudo está organizado, contemplado. 0 fechamento harmônico entre o que há e o que não há, o que é e o que não é. A representação de algo considerado claro, concluso, conhecido. Quais são os efeitos dessa equação harmoniosa perante as desmesuras do humano? Um saber totalizante que limita o universo do dito: os transtornos são fenômenos a priori, independentes do laço social que lhes dá existência. A escolarização de alunos com TGD é pautada pela impossibilidade.

Dessa posição enunciativa resulta um sentido com profundas raízes na cultura escolar especializada: as práticas pedagógicas existem independentes do contexto, das interpretações e das políticas. As diferenças orgânicas, sociais, psíquicas e comportamentais são equacionadas como identidades. De tais identidades derivam currículos e intervenções que justificam, inclusive, as desigualdades escolares. 0 autista! Desse estado, onde se é todos e não se é ninguém, a singularidade é subsumida pela repetição do idêntico. Gadamer afirma que a noção de identidade é nefasta para a justiça social. Em nome de uma diferença lida como identidade, retira-se de cena a alteridade, a diferença como condição de ser. Trata-se do não reconhecimento do outro, de seu apagamento.
0 diferente como diferente. Em meio às nuances do compreender, no encontro com o outro, o plural, talvez seja possível reajustar focos, construir novos outros, ampliando e, talvez, modificando a perspectiva da compreensão: “Eu não tenho explicação, eu não tenho certeza... Tenho uma aposta, um projeto, uma vontade. [...] Um olhar meu, que se sustenta no olhar do Mathias, e nos olhares da escola, da lei”. A experiência hermenêutica advoga a disponibilidade para a abertura, para o imprevisível. Ela aposta no diálogo, mas seu acontecimento requer ouvir o outro como um outro, mantendo sua alteridade. Esse é o desafio. Um desafıo a ser sustentado por políticas de pertencimento, e não pelo

ideal de unicidade como sinônimo de igualdade de direitos. Educação (em abstrato), direito (em abstrato) de todo cidadão (abstrato). Sem rostos. (ARROYO, 2010, p. 1386)

$\mathrm{Na}$ tentativa de articular igualdade e diferença, parece fundamental compreender o papel específico do sistema escolar na produção dos sujeitos diferentes como inferiores, anormais, ineducáveis ou (in)suportáveis. No que diz respeito aos alunos com TGD, tradicionalmente apartados dos processos escolares, as diretrizes inclusivas, as formações, as avaliações e a reprodução acrítica dos manuais classificatórios reproduzem essas formas históricas de pensá-los. No campo da educação especial, as tentativas de reconhecer o diferente têm-se efetivado por meio da violenta abstração, de modo que, para afirmar o direito universal à educação, temos excluído o estranho, o outro, o diferente.

Do texto à vida, as políticas inclusivas de educação especial imprimiram o incremento das matrículas e a atualização de antigos impasses perante o novo, o diferente. Há uma única compreensão desse movimento? Estabelecer um significado inflexível é acreditar que as políticas podem existir independentemente do contexto, dos professores, dos alunos, das escolas. 0 mundo valora os objetos/sujeitos da ma- 
neira como se relaciona com eles. Assim como esse valorar, o relacionar se modifica no tempo. A mesma transição ocorre com a percepção dos intérpretes. 0 texto/aluno assume um sentido para cada leitor/professor em cada momento em que se estabelece contato. A canção só pode existir, ser apreciada e compreendida se alguém a interpretar. Cada artista interpreta a mesma música, a mesma melodia, com seu estilo, influenciado pelo momento histórico em que está inserido. Assim, não existe uma música em-si. Também não existe uma interpretação que soe como a definitiva, imutável daquela melodia. Educação e arte partilham a condição de, em sua atualização, sempre guardarem um lugar para o novo.

Muitos anos depois, em um dos tantos encontros sobre inclusão escolar, um colega diz: "é muito difícil ser alguém. Para Rodrigo, a escola, por um tempo, constitui-se como este lugar possível. É pouco? Não sabemos. Contudo, é nosso dever lembrar que esta é a principal função da escola e das políticas: criar possibilidades de ser".

\section{Referências}

ADORNO, Theodor W. 0 ensaio como forma. In: . Notas de literatura I. São Paulo: Editora 34, 2003. p. 15-45.

AJURIAGUERRA, Julian. Manual de psiquiatria infantil. São Paulo: Atheneu, 1980.

AMERICAN PSYCHIATRIC ASSOCIATION. Manual diagnóstico e estatístico de transtornos mentais (DSM-IV-TR). Porto Alegre: Artes Médicas, 2002.

ARROYO, Miguel. Políticas educacionais e desigualdades: à procura de novos significados. Educação \& Sociedade, Campinas, v. 31, n. 113, p. 1381-1416, out./dez. 2010.

BAPTISTA, Claudio Roberto; CAIADO, Katia; JESUS, Denise. Educação especial: diálogo e pluralidade. Porto Alegre: Mediação, 2008. BRASIL. Ministério da Educação. Secretaria de Educação Especial. Política nacional de educação especial. Brasília, MEC/SEESP, 1994. Ministério da Educação. Política nacional de educação especial na perspectiva da educação inclusiva. Brasília: MEC/SEESP, 2008.

CECCARELLI, Paulo. A contribuição da psicopatologia fundamental para a saúde mental. Revista Latinoamericana de Psicopatologia Fundamental, São Paulo, v. 6, n. 1, p. 13-25, mar./jun. 2003.

FIGUEIRED0, Ana Cristina; TENÓRI0, Fernando. 0 diagnóstico em psiquiatria e psicanálise. Revista Latinoamericana de Psicopatologia Fundamental, São Paulo, v. 3, n. 1, p. 29-43, mar.-jun. 2002.

GADAMER, Hans-Georg. Verdade e método I. Petrópolis: Vozes, 2007 (Original de 1960).

GARCIA, Rosalba. Políticas para a educação especial e as formas organizativas do trabalho pedagógico. Revista Brasileira de Educação Especial, Marília, v. 12, n. 3, p. 299-316, set./dez. 2006.

GRIBOSKI, Claudia. Opinião. Inclusão: Revista de Educação Especial, Brasília, v. 4, n. 1, p. 57, jan./jun. 2008.

HERMANN, Nadja. Breve investigação genealógica sobre o outro. Educação \& Sociedade, Campinas, v. 32, n. 114, p. 137-149, jan./mar. 2011.

KANNER, Léo. Os distúrbios autísticos de contato afetivo. In: ROCHA, Paulina. Autismos. São Paulo: Escuta, 1997. p. 111-170. (Original de 1943) 
MARQUEZAN, Reinoldo. 0 deficiente no discurso da legislação. Campinas: Papirus, 2009.

OMS (Organização Mundial de Saúde). Classificação de transtornos mentais e de comportamento da CID-10: descrições clínicas e diretrizes diagnósticas. Porto Alegre: Artes Médicas, 1993.

RICKES, Simone. Psicanálise e educação: do vazio da determinação como propulsora da produção de sentidos. In: REUNIÃO ANUAL DA ASSOCIAÇÃO DE PÓS-GRADUAÇÃ̃O E PESQUISA EM EDUCAÇÃO, 27., 2004, Caxambu. Anais... Rio de Janeiro: ANPED, 2004. Disponivel em: <http://www.anped.org.br/reunioes/27/gt20/t2011.pdf>. Acesso em: 13 maio 2012.

VASQUES, Carla K. Alice na biblioteca mágica: uma leitura sobre o diagnóstico e a escolarização de crianças com autismo e psicose infantil. 2008. 195 f. Tese (Doutorado em Educação) - Universidade Federal do Rio Grande do Sul, Porto Alegre, 2008.

. Transtornos globais do desenvolvimento e educação: análise da produção científico-acadêmica. In: REUNIÃO ANUAL DA ASSOCIAÇÃO DE PÓS-GRADUAÇÃO E PESQUISA EM EDUCAÇÃO, 31., 2009, Caxambu. Anais... Rio de Janeiro: ANPED, 2009. Disponivel em: <http://www.anped.org.br/reunioes/31ra/1trabalho/GT15-4469--Int.pdf>. Acesso em: 6 ago. 2012.

Recebido em: 22.06.2012

Aprovado em: 18.09.2012

Carla K. Vasques é doutora em Educação pela Universidade Federal do Rio Grande do Sul (UFRGS) e professora da PósGraduação em Educação da mesma universidade.

Simone Moschen é professora da Pós-Graduação em Educação e em Psicologia Social e Institucional, ambos os cursos da Universidade Federal do Rio Grande do Sul (UFRGS).

Roselene Gurski é doutora em Educação pela Universidade Federal do Rio Grande do Sul (UFRGS) e professora do Departamento de Psicanálise e Psicopatologia da mesma universidade. É autora do livro Três ensaios sobre juventude e violência (Escuta, 2012). 